\title{
Effect of Plant Essential Oil on Growth Performance and Immune Function During Rearing Period in Laying Hens
}

\section{-Author(s)}
Gao J!ll
Liu W!
(iD https://orcid.org/0000-0001-9549-3802
Geng B"
Lei Q!,II
(iD) https://orcid.org/0000-0003-2822-7058 (iD) https://orcid.org/0000-0003-1700-9784 (iD) https://orcid.org/0000-0001-5471-3653
Han $\mathrm{H}^{\prime, 11}$
Zhou Y',III
Liu J!"ll
Cao D.,11!
Li H, $\mathrm{H}^{\prime, 11}$
Li F,,III
(D) https://orcid.org/0000-0002-3307-5063
(iD) https://orcid.org/0000-0001-8789-3582
(iD) https://orcid.org/0000-0002-5415-2363
(iD) https://orcid.org/0000-0003-2070-9925
(iD) https://orcid.org/0000-0001-6488-2215
(iD) https://orcid.org/0000-0002-5463-9542
Poultry Institute, Shandong Academy of Agricultural Sciences, Jinan, 250023, Shandong, China.
" Sericultural Research Institute of Shandong Province, Yantai, 264002, Shandong, China.
III Poultry Breeding Engineering Technology Center of Shandong Province, Jinan/250023, Shandong, China.

*These authors contributed equally to this work.

\section{Mail Address}

Corresponding author e-mail address Jinbo-Gao

Sericultural Research Institute of Shandong Province, Yantai, 264002, Shandong,

China.

Email: jinbogao1985@163.com

\section{- Keywords}

Laying hens, plant essential oil, production performance, immune function.

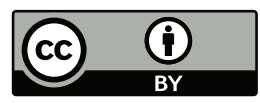

Submitted: 25/December/2019

Approved: 07/July/2020

\section{ABSTRACT}

The effects of plant essential oil (PEO) on the production performance and immune function of laying hens were evaluated to provide theoretical basis for promoting the natural plant extracts. Eight thousand 1-day-old healthy laying hens were randomly divided into a control group or PEO group, with four replicates per treatment and 1000 hens per replicate. The PEO diet was supplemented with $3 \mathrm{~g} / \mathrm{kg}$ plant extract. Diets were fed for 56 days. The tibia length and keel length were detected on an empty stomach at the end of the trial. Blood samples were collected on the $28^{\text {th }}$ and $56^{\text {th }}$ days to detect the level of C3, C4, IL-1, IL-2, IL-17 and immunoglobulin in the serum. The results showed that, compared with the control, PEO supplementation significantly increased the weight gain rate (WGR) at the $2^{\text {nd }}, 4^{\text {th }}, 5^{\text {th }}$ and $7^{\text {th }}$ week $(p<0.05)$, and decreased the WGR at the $3^{\text {rd }}$ and $6^{\text {th }}$ week. The tibial length was significantly increased at the $3^{\text {rd }}, 5^{\text {th }}, 6^{\text {th }}$ and $7^{\text {th }}$ week $(p<0.01)$, and also the keel length at the $5^{\text {th }}$ and $7^{\text {th }}$ week in PEO group. The concentration of $\lg$ and $\operatorname{lgM}$ also significantly influenced with PEO supplementation, but there was no significant difference in the complements, C3 and C4, and the IL levels between days 28 and 56 . Moreover, no significant difference was observed in body weight and immune organ on day 56. Therefore, we conclude that the addition of PEO could improve the production performance and immune function in laying hens.

\section{INTRODUCTION}

Plant essential oil (PEO), as a feed additive extract that has been favored in recent years (Brenes et al., 2010), and have been conducted in many studies. It was reported that plant essential oils, probiotics and enzymes can be used as healthy substitutes for antibiotics, which can improve the balance of intestinal microbiome and maintain the intestinal homeostasis (Patterson et al., 2003; Vondruskova et al., 2010). In livestock sector, PEO was initially added in the diet as a flavor enhancer to induce animal feeding, which in turn can improve the feeding efficiency and growth performance (Franz et al., 2010). In the process of layer breeding, the growth level of the brooding period is directly related to the laying performance and production performance of the whole life. Therefore, how to develop and utilize plant essential oils to improve the growth performance of laying hens is the key technology urgently needed in the laying hen breeding industry at present.

With the deepening of the research, it was found that essential oil (EO) also has a wide range of physiological functions, such as sterilization, antioxidation, anti-inflammation, anti-viral action and so on (Suntres et al., 2015). Because of its rich and varied natural properties, PEO has a broad application prospect as a substitute for antibiotics in the field of animal production. Studies have shown 
Gao J, Liu W, Geng B, Lei Q, Han H, Zhou Y, Liu J, Cao D, Li H, Li F
Effect of Plant Essential Oil on Growth Performance and Immune Function During Rearing Period in Laying Hens that the addition of $40 \mathrm{mg} / \mathrm{kg}$ oregano and lavender leaf and lavender mixed essential oil or $500 \mathrm{mg} / \mathrm{kg}$ oregano essential oil in broilers diets can effectively reduce the discharge of coccidian eggs in feces and reduce the degree of mucosal damage caused by coccidia infection (Bozkurt et al., 2014; Mohiti-Asli et al., 2015). When garlic and thyme essential oil were added to the diet of laying hens, the egg weight and yolk color increased significantly, which could enhance the production performance (Ghasemi et al., 2010). In addition, the dietary supplementation of plant essential oil could improve the immune function of animals (Li et al., 2012; Awaad et al., 2014). In the process of layer breeding, the growth level of the brooding period is directly related to the laying performance and production performance of the whole life. therefore, how to develop and utilize plant essential oils to improve the growth performance of laying hens is the key technology urgently needed in the laying hen breeding industry at present. In the present study, plant essential oils have attracted much attention in animal husbandry production. However, there are few reports on the effect of plant essential oils on the growth performance and immune function in laying hens. Therefore, in this study, we evaluated the effect of plant essential oils on the growth performance and immune function of laying hens. This study provides data support and theoretical basis for the application of plant essential oils in layer production.

\section{MATERIALS AND METHODS}

\section{Ethics statement}

All animal procedures performed in this study were reviewed, approved, and supervised by the Animal Ethics committee of Shandong Academy of Agricultural Science (Permit No.:2018412).

\section{Plant essential oil}

Coated plant essential oil products were provided by the Institute of Animal Husbandry and Veterinary Medicine, Shandong Academy of Agricultural Sciences. The effective components are the mixture of flavonoids and linalool, with approximately the content of flavonoids $\geq 12 \%$, and linalool $\geq 10 \%$.

\section{Instruments and equipment}

The following instruments and kits were used in this study: Enzyme label instrument (ELX800), BioTek Baote Company; Desktop centrifuge (TGL-16G), Shanghai Anting Scientific Instrument Factory; YQX- ॥ anaerobic incubator, Shanghai Kanghua Biochemical Instrument Factory; Chicken Immunoglobulin A ( $\lg A)$, Immunoglobulin G (IgG), and Immunoglobulin M (IgM) ELISA Kits from Jiyinmei company.

\section{Experimental animal}

Eight thousand 1-day-old Hailan brown laying hens were randomly divided into two groups (control group or PEO group), Each group had 4 repetitions, 1000 repetitions. The PEO group was supplemented with $0.3 \%$ coated plant essential oil in the basal diet. Under conventional conditions, the feeding conditions, feeding methods and feed amount of each group were equal. The trial period was 56 days, with a pretrial period of 5 days.

\section{Time and place of trial}

The experiment was carried out in Huasheng Jifu laying hens farm in Haiyang City from April 24 to June 30, 2018.

\section{Determination of production performance}

The body weight of the hens was measured every weekend (on days 7, 14, 21, 28, 35, 42, 49), after fasting for 12 hours, and the average weekly weight gain rate (WGR) of repeated laying hens were calculated. The tibia length (TL), and keel length (KL) were detected every weekend.

\section{Immune organ index}

At the end of the experiment (on day 56), 56 chickens in each group were randomly selected, followed by fasting for 12 hours with free drinking water, and weighed and slaughtered. Thymus, spleen, bursa of Fabricius and liver, were completely dissected out and wiped out fat and other tissues and sucked the surface liquid. The fresh weight was measured by electronic balance, and the immune organ index was calculated.

Immune organ index = immune organ fresh weight (g) / premortem fasting live weight $(\mathrm{kg})$.

\section{Immunological factors}

On the 28th and 56th day, 20 chickens were randomly selected from each group, and $5 \mathrm{~mL}$ of blood was collected from the brachial vein (medial wing vein). The level of immunoglobulin $\mathrm{G}(\mathrm{lgG})$, immunoglobulin $M$ (IgM), interleukin-1 (IL-1), interleukin-2 (IL-2), interleukin-17(IL-17), Complement C3(C3) and Complement $\mathrm{C} 4(\mathrm{C} 4)$ was detected in serum, with ELISA kit (Wuhan Genmei Technology Co., Ltd.), according to the instructions. 


\section{Statistical Analysis}

Experimental data were analyzed by One-way analysis of variance (ANOVA) using the SPSS (2008) statistical software (Ver.16.0 for windows, SPSS Inc., Chicago, IL) with a pen (cage) as an experimental unit. Differences among treatments were examined using the Tukey-Kramer's multiple range tests, which were considered significant when the P-value was less than 0.05. The means and standard errors of means (SEM) were also presented.

\section{RESULTS}

\section{Production performance during brooding stage}

The data of WGR showed that except for the 21th, 28th and 42nd day, the weight gain rate in PEO group during other days was significantly higher than that of the control group $(p<0.05)$. The average weekly growth rate of the experimental group was $41.84 \%$, and that of the control group was $41.14 \%$. There was no significant difference in tibial length between the 7th, 14th and 28th day, but the tibial length of the experimental group was significantly higher than that of the control group at the 21th, 35th, 42nd and 49th day. The keel length of the experimental group was significantly higher than that of the control group at the 35th and 49th day, but there was no significant difference during the other days (Table 1).

\section{Immune Organ Index during brooding stage}

Our research results show that there was no statistically significant difference in the body weight (BW), spleen index (SI), thymus index ( $\mathrm{TI})$ and bursa

Table 1 - Production performance during brooding period.

\begin{tabular}{lcccccccc}
\hline Item & & $2 d$ & $14 d$ & $21 d$ & $28 d$ & $35 d$ & $42 d$ & $49 d$ \\
\multirow{2}{*}{ WGR \% } & PEO & - & $77.09 \pm 3.88^{\mathrm{a}}$ & $52.51 \pm 4.63^{\mathrm{b}}$ & $34.93 \pm 2.88^{\mathrm{a}}$ & $41.05 \pm 3.08^{\mathrm{a}}$ & $22.64 \pm 9.58^{\mathrm{a}}$ & $22.81 \pm 9.45^{\mathrm{a}}$ \\
& Control & - & $74.83 \pm 5.21^{\mathrm{b}}$ & $60.01 \pm 7.12^{\mathrm{a}}$ & $34.68 \pm 2.00^{\mathrm{a}}$ & $31.85 \pm 3.11^{\mathrm{b}}$ & $26.94 \pm 7.08^{\mathrm{a}}$ & $18.51 \pm 5.76^{\mathrm{b}}$ \\
\hline \multirow{2}{*}{$\mathrm{TL}(\mathrm{mm})$} & PEO & $36.65 \pm 0.94^{\mathrm{a}}$ & $44.86 \pm 1.32^{\mathrm{a}}$ & $52.69 \pm 1.59^{\mathrm{a}}$ & $58.92 \pm 4.61^{\mathrm{a}}$ & $67.88 \pm 2.01^{\mathrm{a}}$ & $75.92 \pm 2.17^{\mathrm{a}}$ & $80.53 \pm 2.62^{\mathrm{a}}$ \\
& Control & $36.58 \pm 0.88^{\mathrm{a}}$ & $44.19 \pm 1.77^{\mathrm{a}}$ & $52.22 \pm 1.59^{\mathrm{b}}$ & $58.52 \pm 1.91^{\mathrm{a}}$ & $67.23 \pm 1.96^{\mathrm{b}}$ & $74.78 \pm 1.69^{\mathrm{b}}$ & $79.15 \pm 2.84^{\mathrm{b}}$ \\
\hline \multirow{2}{*}{$\mathrm{KL}(\mathrm{mm})$} & PEO & - & - & $46.51 \pm 1.80^{\mathrm{a}}$ & $50.92 \pm 1.91^{\mathrm{a}}$ & $58.23 \pm 1.95^{\mathrm{a}}$ & $62.55 \pm 3.73^{\mathrm{a}}$ & $71.10 \pm 3.78^{\mathrm{a}}$ \\
& Control & - & - & $46.36 \pm 1.96^{\mathrm{a}}$ & $50.28 \pm 2.42^{\mathrm{a}}$ & $57.30 \pm 2.79^{\mathrm{b}}$ & $63.14 \pm 2.69^{\mathrm{a}}$ & $69.41 \pm 3.75^{\mathrm{b}}$ \\
\hline
\end{tabular}

$\mathrm{a}, \mathrm{b}$ Means in the same line with different letters were significantly different $(p<0.05)$. Data represented mean $\pm S E M ; n=60$ per group. WGR=weight gain rate, TL=tibial length, $\mathrm{KL}=$ keel length.

index (BI) between the PEO group and the control group. The liver index (LI) in the PEO group was significantly higher than that in the control group (Table 2).

Table 2 - Immune Organ Index during brooding stage.

\begin{tabular}{lccccc}
\hline Item & BW $(\mathrm{kg})$ & $\mathrm{SI}$ & $\mathrm{TI}$ & $\mathrm{LI}$ & $\mathrm{BI}$ \\
\hline PEO & $0.750 \pm 0.059^{\mathrm{a}}$ & $2.65 \pm 0.11^{\mathrm{a}}$ & $3.66 \pm 0.21^{\mathrm{a}}$ & $25.11 \pm 0.56^{\mathrm{a}}$ & $3.76 \pm 0.22^{\mathrm{a}}$ \\
Control & $0.757 \pm 0.056^{\mathrm{a}}$ & $2.67 \pm 0.10^{\mathrm{a}}$ & $4.07 \pm 0.14^{\mathrm{a}}$ & $21.45 \pm 0.36^{\mathrm{b}}$ & $4.01 \pm 0.17^{\mathrm{a}}$ \\
$p$ value & 0.6823 & 0.8808 & 0.1153 & $<.0001$ & 0.0503 \\
\hline
\end{tabular}

$a, b$ Means in the same line with different letters were significantly different $(P<0.05)$. Data represented mean $\pm \mathrm{SEM} ; \mathrm{n}=30$. BW=body weight, $\mathrm{Sl}=$ spleen index, $\mathrm{Tl}=$ thymus index, $\mathrm{Ll}=$ liver index, $\mathrm{Bl}=$ bursa index.

\section{Detection of serum immunoglobulin con- centration}

The results of serum immunoglobulin showed that the concentrations of IgG and IgM in PEO group were significantly higher than that of the control group at 28 days $(p=0.0020, p<0.01)$. Whereas, the $\lg G$ concentration in the serum of PEO group was significantly lower than that of the control group at 56 days $(p=0.0018, p<0.01)$. There was no significant difference in the serum IgM concentration between the two groups. The highest content of immunoglobulin appeared in PEO group during the whole experimental period (Table 3).

Table 3 - The immunoglobulin concentration in serum.

\begin{tabular}{|c|c|c|c|c|}
\hline \multirow{2}{*}{ Item } & \multicolumn{2}{|c|}{$28 d$} & \multicolumn{2}{|c|}{$56 \mathrm{~d}$} \\
\hline & $\operatorname{lgG}(\mu \mathrm{g} / \mathrm{ml})$ & $\operatorname{lgM}(\mathrm{ng} / \mathrm{ml})$ & $\operatorname{lgG}(\mu \mathrm{g} / \mathrm{ml})$ & $\operatorname{lgM}(\mathrm{ng} / \mathrm{ml})$ \\
\hline PEO & $19.43 \pm 0.41^{\mathrm{a}}$ & $408.51 \pm 12.46^{a}$ & $14.65 \pm 0.33^{a}$ & $339.67 \pm 8.52^{a}$ \\
\hline Control & $17.62 \pm 0.38^{b}$ & $347.11 \pm 8.11^{b}$ & $16.45 \pm 0.48^{b}$ & $359.52 \pm 10.03^{a}$ \\
\hline$p$ value & 0.0020 & $<.0001$ & 0.0018 & 0.1361 \\
\hline
\end{tabular}

$a, b$ Means in the same line with different letters were significantly different $(p<0.05)$. Data represented mean $\pm S E M ; n=30$ per group. 


\section{Detection of Serum complement concen- tration}

The quantitative results of serum complement components showed (Table 4) that there was no significant difference in the concentration of complement components $\mathrm{C} 3$ and $\mathrm{C} 4$ between the PEO group and the control group on the 28th day $(p>0.05)$. On the 56th day, the complement C3 in the PEO group was significantly higher than that in the control group $(p=0.0457, p<0.05)$, but the complement $\mathrm{C} 4$ in the experimental group was higher than that in the control group at the early and late stages, even though it was not statistically significant $(p>0.05)$.

Table 4 - Effect of PEO supplementation on the serum complement concentrations of laying hens at 28d and 56d.

\begin{tabular}{|c|c|c|c|c|}
\hline \multirow{2}{*}{ Item } & \multicolumn{2}{|c|}{$28 d$} & \multicolumn{2}{|c|}{$56 d$} \\
\hline & $\mathrm{C} 3(\mathrm{pg} / \mathrm{ml})$ & C4 (pg/ml) & C3 (pg/ml) & C4 (pg/ml) \\
\hline PEO & $2830.32 \pm 61.29^{a}$ & $807.52 \pm 24.91^{\mathrm{a}}$ & $3540.5 \pm 90.16^{a}$ & $783.20 \pm 20.38^{a}$ \\
\hline Control & $2717.47 \pm 61.90^{a}$ & $769.27 \pm 21.57^{a}$ & $3307.7 \pm 72.13^{b}$ & $738.84 \pm 20.86^{a}$ \\
\hline$p$ value & 0.2054 & 0.2655 & 0.0457 & 0.1445 \\
\hline
\end{tabular}

$a, b$ Means in the same line with different letters were significantly different ( $p<0.05)$. Data represented mean $\pm S E M ; n=30$ per group.

\section{Serum interleukin levels}

The interleukin levels showed that there was no significant difference in the levels of IL-1, IL-2 and IL-17 between the two groups on the 28th day and the 56th day, but the IL levels of PEO group were slightly higher than those of the control group on these days, even though the difference was not statistically significant ( $p>0.05$ ) (Table 5).

Table 5 - Effect of PEO supplementation on serum interleukin levels in laying hens at 28d and 58d.

\begin{tabular}{|c|c|c|c|c|c|c|}
\hline \multirow{2}{*}{ Item } & \multicolumn{3}{|c|}{$28 d$} & \multicolumn{3}{|c|}{$56 \mathrm{~d}$} \\
\hline & $\mathrm{IL}-1(\mathrm{pg} / \mathrm{ml})$ & IL-2 (pg/ml) & IL-17 (pg/ml) & $\mathrm{IL}-1(\mathrm{pg} / \mathrm{ml})$ & $\mathrm{IL}-2(\mathrm{pg} / \mathrm{ml})$ & IL-17 (pg/ml) \\
\hline PEO & $108.37 \pm 2.67^{a}$ & $164.66 \pm 5.11^{a}$ & $80.25 \pm 6.10^{a}$ & $106.56 \pm 2.46^{a}$ & $164.06 \pm 3.75^{a}$ & $80.37 \pm 1.85^{a}$ \\
\hline Control & $103.39 \pm 2.43^{a}$ & $164.34 \pm 4.02^{\mathrm{a}}$ & $79.79 \pm 4.73^{\mathrm{a}}$ & $110.51 \pm 2.44^{a}$ & $160.61 \pm 4.96^{a}$ & $75.53 \pm 1.72^{\mathrm{a}}$ \\
\hline$p$ value & 0.1764 & 0.9607 & 0.8912 & 0.2668 & 0.5745 & 0.0722 \\
\hline
\end{tabular}

$a, b$ Means in the same line with different letters were significantly different ( $p<0.05)$. Data represented mean $\pm S E M ; n=30$ per group.

\section{Serum anti-viral antibody levels}

The specific anti-viral antibody assays against H9 Influenza virus and Newcastle disease virus (NDV) showed that (Table 6) the level of H9 subtype (H9) of Influenza virus antibody in the test group was significantly higher $(p<0.05)$ than that in the control group on the 28th and 56th day, but there was no significant difference in the Newcastle disease virus (NDV) antibody level between the test group and the control group on the 28th and 56th day ( $p>0.05$ ).

Table 6 - Serum anti-viral antibody levels of H9 Influenza virus and Newcastle disease virus (NDV).

\begin{tabular}{|c|c|c|c|c|}
\hline \multirow{2}{*}{ Item } & \multicolumn{2}{|c|}{$28 d$} & \multicolumn{2}{|c|}{$56 d$} \\
\hline & ND & $\mathrm{H} 9$ & ND & $\mathrm{H} 9$ \\
\hline PEO & $6.15 \pm 0.31^{a}$ & $2.54 \pm 0.36^{a}$ & $8.41 \pm 0.13^{a}$ & $10.12 \pm 0.17^{a}$ \\
\hline Control & $5.95 \pm 0.38^{a}$ & $1.54 \pm 0.28^{b}$ & $8.50 \pm 0.15^{a}$ & $9.42 \pm 0.29^{b}$ \\
\hline$p$ value & 0.6913 & 0.0313 & 0.6475 & 0.0410 \\
\hline
\end{tabular}

$a, b$ Means in the same line with different letters were significantly different $(p<0.05)$. Data represented mean $\pm S E M ; n=100$ per group.

\section{DISCUSSION}

\section{Production performance}

Natural plant extracts have been showing promising effects to promote the growth of poultry (Jamroz et al., 2005; Windisch et al., 2008), and the addition of flavonoids to the diet could improve the growth performance of broilers (Starčević et al., 2014). Ouyang et al. (2016) found that alfalfa extract supplemented with $15 \mathrm{mg}$ flavonoids/kg feed had a positive effect on the average daily gain and feed conversion rate of broilers. Chen et al.'s (2016) study showed that dietary supplementation of $0.3 \mathrm{~g} / \mathrm{kg}$ alfalfa extract ( $81 \%$ flavonoids) could promote the growth of geese, increased feed intake and nitrogen utilization efficiency, and significantly increased the strength and weight of tibia, thus reduced the incidence of leg diseases.

Some previous studies have shown that the use of plant essential oil in poultry breeding could 
increase feed intake and efficiency, increase the secretion of digestive enzymes, and promote intestinal microecological balance (Jang et al., 2008; Lee et al., 2003; Liolios et al., 2009). This study proved that the addition of plant essential oils to the diet can improve the growth performance of laying hens, which may be due to the fact that plant essential oils can promote the secretion of digestive enzymes and other enzymes, and then increase the absorption of nutrients in the diet. To achieve the effect of promoting growth. This is consistent with reports of Fardos et al. (2019), where the addition of plant essential oils to the diet showed considerable improvement in the body weight and growth rate of chickens. These marked variations in growth rate weight gain factors are mediated by and flavonoids in plant essential oils, which can affect and influence the intestinal morphology and promote intestinal mucosal absorption (Awad etal., 2011; Viveros et al. 2011). Other studies have shown that flavonoids in the form of glycosides play a key role in plant growth and development by regulating the homeostasis of growth hormones (Yin et al. 2014; Kuhn et al. 2016). To sum up, plant essential oils has a significant effect on improving the production performance of laying hens and has a broad prospect in its breeding capacity. The development and utilization of plant essential oils are of great significance to promoting the poultry industry with healthy development of laying hens.

\section{Immunity}

A large number of studies have reported that plant essential oils have extensive potential antibacterial activity. So it is speculated that the level of immune response will be improved after feeding plant essential oils in the brooding period of laying hens. The thymus, spleen and bursa of Fabricius are important immune organs of poultry and are the main sites that secrete many kinds of immune activity factors (Fan et al., 2013), and their status is closely related to immune function. Ravis et al. (1988) have reported that the relative weight of immune organs can be used to evaluate their immune status, and a larger weight of immune organs usually represents a stronger immune function to some extent. Therefore, the immune organ index is often used to evaluate the immunity level of poultry (Heckert et al., 2002). The liver is one of the main organs to regulate the metabolism of the body. It can secrete a variety of metabolic enzymes and is also the main organ of detoxification and immune defense in the body (Chao et al., 2019). This study confirmed that the addition of plant essential oils to the diet could significantly increase the liver index of the experimental group, indicating that plant essential oils may regulate the production of immune coping factors through the liver, and then achieve the goal of regulating immune function. IgG and $\lg M$ are important factors that affect the immune response to many microbes and prevent infections (Zhao et al., 2017). From the increase of IgG and IgM content in brooding hens in this study, it can be seen that adding plant essential oils to the diet can promote the secretion of immunoglobulin, thus protect the body from harmful bacteria and improve the immunity and disease resistance of the body. These results are similar with Özek. Özek et al. (2019), state that adding mixed essential oils (oregano essential oil, lauryl essential oil, sage essential oil, myrtle essential oil, fennel essential oil, citrus peel essential oil) to 52-day-old layers' diets could increase the antibody levels of Newcastle disease virus and infectious bursal virus in blood. Hao et al. (2018) adding 20mg/kg Daidzein to breeder chickens could increase serum IgA and IgG levels and serum NDV antibody titer in 21-day-old broilers. It was believed that the addition of plant essential oil to the diet can promote the secretion of immunoglobulin and improve the antibody titer.

The complement system is an efficient amplification system of immune activity in the body, which plays a very important role in the defense response and immune regulation of the body against microbial infections. At the same time, it can also mediate the traumatic immunopathological reactions. In recent years it has been found that the complement has a regulatory effect on immunity. In terms of immune complex, the complement can prevent the precipitation and dissolution of immune complex and can accelerate the clearance of immune complex. In addition, the complement also has a series of regulatory effects on the cellular immunity and humoral immunity. The complement system includes many complement components. C3 and C4 are inherently important components of the complement system, which exists in body fluids to participate in the complement activation cascade. C3 is mainly synthesized by the liver, but can also be synthesized by macrophages, and $\mathrm{C} 4$ is synthesized exclusively by macrophages (book). Our results showed that the addition of plant essential oil to the diet of laying hens could increase the concentration of complement components $C 3$ and C4 in blood, which indicated that the plant essential oil could promote the immune function of laying hens (Wang et al., 2001). 
Effect of Plant Essential Oil on Growth Performance and Immune Function During Rearing Period in Laying Hens
Cytokines also play an important role in the process of immune regulation, such as IL-1, IL-2, IL-6 and TNF, which can act on the hypothalamus, pituitary, adrenal gland and gonads. It has a variety of activities such as immune regulation, anti-inflammation and so on (Parkin et al., 2001). Interleukin-1 (IL-1) is also known as lymphocyte activating factor (LAF), B cell activating factor (BAF), thymocyte proliferation factor (TPF) and so on. At present, it is believed that the main role of $\mathrm{IL}-1$ is to mediate inflammatory response, regulation of immune response, elicit anti-tumor effect and so on. IL-1 plays a wide range of regulatory roles in immune response. It can induce lymphocytes to release lymphokines, enhance the antigen binding ability of $\mathrm{T}$ cells, and enhance the activity of natural killer cells (NK cells). However, IL-1 alone does not have any stimulating effect on NK cells. Only IL-1 plus IL-2 or interferon, or both, can significantly enhance the activity of NK cells and could promote B cells to proliferate and differentiate into antibody-producing cells (Kuby et al., 1997). Interleukin 2 (IL-2) can induce $\mathrm{T}$ cell proliferation and maintain the continuous growth of $T$ cells in vitro, so it was once called $T$ cell growth factor (TCGF). This study found that adding plant essential oil to the diet of laying hens can increase the concentration of IL-1 and IL-2 in serum, although the difference is not statistically significant, it may plays an important role in the antibody mediated immune response by stimulating $B$ lymphocytes, which also confirms the fact that the addition of plant essential oil can improve the level of antibody.

\section{CONCLUSION}

We concluded that $0.3 \%$ coated PEO supplementation in diet could enhance immunity, improve antibody levels, and promote the growth performance in laying hens, which indicates a great potential utilization value of PEO.

\section{ACKNOWLEDGEMENTS}

This study was funded by the Jinan Layer Experiment Station of China Agriculture Research System (CARS40-S12), the Research and Demonstration on Key Technologies of Precision Management and Control of Laying Hen Healthy Breeding in Key R \& D Projects of Shandong Province(2019JZZY020611), the Agricultural scientific and technological innovation project of Shandong Academy of Agricultural Sciences (CXGC2016A04), the Shandong Provincial Key Laboratory of Special Construction Project
(SDKL201810) and Construction of Subjects and Teams of Institute of Poultry Science (CXGC2018E11).

\section{REFERENCES}

Awaad $\mathrm{MHH}$, Elmenawey M, Ahmed KA. Effect of a specific combination of carvacrol, cinnamaldehyde and capsicum oleoresin on the growth performance, carcass quality and gut integrity of broiler chicken. Veterinary Word 2014;7(5):284-290.

Awad W, Ghareeb K, Böhm J. Evaluation of the chicory inulin efficacy on ameliorating the intestinal morphology and modulating the intestinal electrophysiological properties in broiler chickens. Journal of Animal Physiology and Animal Nutrition 2011;95:65-72.

Bozkurt M, Aysul N, KüçükyilmazK, Aypak S, Ege G, Çatli AU, et al. Efficacy of in-feed preparations of an anticoccidial, multienzyme, prebiotic, probiotic and herbal essential oil mixture in healthy and Eimeria sppinfected broilers. Poultry Science 2014;93(2):389-399.

Brenes A, Roura E. Essential oils in poultry nutrition: Main effects and modes of action. Animal Feed Science and Technology 2010;158(1):1-14.

Chen Y, Gong X, Li G, Lin M, Huo Y, Li S, et al. Effects of dietary alfalfa flavonoids extraction on growth performance, organ development and blood biochemical indexes of Yangzhou geese aged from 28 to 70 days. Animal Nutrition and Feed Technology 2016;2:318-322.

Han C, Wei Y, Wang X, Ba C, Shi W. Protective effect of Salvia miltiorrhiza polysaccharides on liver injury in chickens. Poultry Science 2019;98(9):3496-3503.

Franz C, Baser K, Windisch W. Essential oils and aromatic plants in animal feeding- A European perspective. A review. Flavour and Fragrance Journal 2010;25(5):327-340.

Fardos AM, Hassan I, Elshimaa M, Roushdy, Asmaa TY, Asmaa W, et al. Growth performance, antioxidant capacity, lipid-related transcript expression and the economics of broiler chickens fed different levels of rutin. Animals 2019;9(7):2-13.

Fan YP, Lu Y, Wang DY, Liu JG, Song XP, Zhang WM, et al. Effect of epimedium polysaccharide-propolis flavone immunopotentiator on immunosuppression induced by cyclophosphamide in chickens. Cellular Immunology 2013;281:37-43.

Fan H, Lv Z, Gan L, Guo Y. The transcriptomics-related mechanisms of supplementing laying broiler breeder hens with dietary daidzein to improve the immune function and growth performance of offspring. Journal of Agricultural and Food Chemistry 2018;2:1-48.

Ghasemi R. Adding medicinal herbs including garlic (Allium sativum) and thyme (Thymus vulgaris) to diet of laying hens and evaluating productive performance and egg quality characteristics. American Journal of Animal \& Veterinary Sciences 2010;5(2):151-154.

Heckert RA, Estevez I, Russek-Cohen E, Pettit-Riley R. Effects of density and perch availability on the immune status of broilers. Poultry Science 2002;81:451-457.

Jamroz D, Wiliczkiewicz A, Wertelecki T, Orda J, Skorupińska J. Use of active substances of plant origin in chicken diets based on maize and locally grown cereals. British Poultry Science 2005;46(4):485-493.

Jang IS, Ko YH, Kang SY, Lee CY. Effect of commercial essential oil on growth performance, digestive enzyme activity and intestinal microflora population in broiler chickens. Animal Feed Science and Technology 2007;134:304-315.

Kuby J. Immunology. 4th ed. New York: W.H. Freeman \& Company; 1997. 
Gao J, Liu W, Geng B, Lei Q, Han H, Zhou Y, Liu J, Cao D, Li H, Li F
Kuhn BM, Errafi S, Bucher R, Dobrev P, Geisler M, Bigler L, etal . 7-Rhamnosylated flavonols modulate homeostasis of the plant hormone auxin and affect plant development. Journal of Biological Chemistry 2016;291:5385- 5395.

Lee KW, Everts H, Kappert HJ, Yeom KH, Beynen AC. Dietary carvacrol lowers body weight gain but improves feed conversion in female broiler chickens. Journal of Applied Poultry Research 2003;12:394-399.

Li SY, Ru YJ, Liu M, Xu B, Péron A, Shi XG. The effect of essential oils on performance, immunity and gut microbial population in weaner pigs. Livestock Science 2012;145(1):119-123.

Liolios CC, Gortzi O, Lalas S, Tsaknis J, Chinou I. Liposomal incorporation of carvacrol and thymol isolated from essential oil of Origanum dictamnus L. and in vitro antimicrobial activity. Food Chemistry 2009;112:77-83.

Mohiti-Asli M, Ghanaatparast-Rashti M. Dietary oregano essential oil alleviates experimentally induced coccidiosis in broilers. Preventive Veterinary Medicine 2015;120(2):195-202.

Mongini PK, Jackson AE, Tolani S, Fattah RJ, Inman JK. Role of complementbinding CD21/CD19/CD21 in enhancing human B cell protection from Fas-mediated apoptosis. Immunology 2003;171(10):5244-5254.

Ouyang $K$, Xu M, Jiang Y, Wang W. Effects of alfalfa flavonoids on broiler performance, meat quality, and gene expression. Canadian Journal of Animal Science 2016;96:332-341.

Özek K, Wellmann K T, Ertekin B, Tarım B. Effects of dietary herbal essential oil mixture and organic acid preparation on laying traits, gastrointestinal tract characteristics, blood parameters and immune response of laying hens in a hot summer season. Journal of Animal and Feed Sciences $2011 ; 20(4): 575-586$

Parkin J, Cohen B. An overview of the immune system. Lancet 2001;357:1777-1789.

Patterson JA, Burkholder KM. Application of prebiotics and probiotics in poultry production. Poultry science 2003;82(4):627-631.
Effect of Plant Essential Oil on Growth Performance

and Immune Function During Rearing Period in

Laying Hens

Ravis WR, Parsons DL, Wang SJ. Buffer and $\mathrm{pH}$ effects on propranolol binding by human albumin and $\alpha 1$-acid glycoprotein. Journal of Pharmacy \& Pharmacology 1988;40:459-463.

Starčević K, Brozić D, Maurić M, Stojević Z, Željko M, Bajić M, et al. Production performance, meat composition and oxidative susceptibility in broiler chicken fed with different phenolic compounds. Journal of the Science of Food and Agriculture 2014;95(6):1172-1178.

Suntres ZE, Coccimiglio J, Alipour M. The bioactivity and toxicological actions of carvacrol. Critical Reviews in Food Science and Nutrition 2015;(55):304-318.

Viveros A, Chamorro S, Pizarro M, Arija I, Centeno C, Brenes A. Effects of dietary polyphenol-rich grape products on intestinal microflora and gut morphology in broiler chicks. Poultry Science 2011;90:566-578.

Vondruskova H, Slamova R, Trckova M, Zraly Z, Pavlik I. Alternatives to antibiotic growth promoters in prevention of diarrhoea in weaned piglets: A review. Veterinarni Medicina 2010;55(5):199-224.

Wang R, Wang X, Han W. Modern immunology of animal. $2^{\text {nd }}$ ed. Jinlin; 2001. p.73-89.

Windisch W, Schedle K, Plitzner C, Kroismayr A. Use of phytogenic products as feed additives for swine and poultry. Journal of Animal Science 2008;86:140-148

Yin R, Han K, Heller W, Albert A, Dobrev PI, Zazimalova E, et al. Kaempferol 3-O-rhamnoside-7-O-rhamnoside is an endogenous flavonol inhibitor of polar auxin transport in Arabidopsis shoots. New Phytologist 2014;201:466- 475 .

Zhao XH, Chen ZD, Zhou S, Song XZ, Ouyang KH, Pan K, et al. Effects of daidzein on performance, serum metabolites, nutrient digestibility, and fecal bacterial community in bull calves. Animal Feed Science and Technology 2017;225:87-96. 
